\title{
Influência de doses de fósforo no fluxo difusivo em solos de Alagoas ${ }^{1}$
}

Adelmo L. Bastos ${ }^{2}$, José P. V. da Costa ${ }^{3}$, Ivandro de F. da Silva ${ }^{4}$, Roberto W. C. Raposo ${ }^{4}$ \& Jacob S. Souto ${ }^{5}$

\section{RESUMO}

Objetivando avaliar o efeito de diferentes doses de fósforo sobre o fluxo difusivo deste elemento em amostras de solos do Estado de Alagoas, conduziu-se um experimento em laboratório, no Centro de Ciências Agrárias da Universidade Federal de Alagoas, município de Rio Largo, AL. Os solos utilizados foram classificados como Latossolo Amarelo coeso (LAx), Argissolo Acinzentado (PAC), Neossolo Flúvico (RU), Neossolo Quartzarênico RQ), Luvissolo Crômico órtico (TCo) e Luvissolo Crômico pálico (TCp). Realizaram-se análises químicas, físicas e mineralógicas. O P remanescente foi determinado na solução de equilíbrio e a CMAP o foi em função do fósforo remanescente, utilizando-se, como unidades experimentais, anéis de PVC, que serviram como câmara de difusão. As doses de fósforo corresponderam a 0, 10, 20 e $30 \%$ da CMAP. Para avaliação do fluxo difusivo de fósforo dos solos, se utilizaram papel de troca aniônica e a metodologia de papel-filtro impregnado com óxido de ferro. O ensaio consistiu em um arranjo fatorial $(6 \times 4)$ correspondendo, respectivamente, a seis solos e quatro doses de fósforo. Os solos mais arenosos (RQ e RU) e a maior dose usada indicaram sempre os maiores fluxos difusivos de fósforo.

Palavras-chave: CMAP, FCP, difusão

\section{Influence of phosphorus doses in diffusive flow in the soils of Alagoas}

\begin{abstract}
The effect of distinct doses of phosphorus was evaluated on the diffusion of this element in soil samples from the State of Alagoas. The experiment was performed in the laboratory of the Centro de Ciências Agrárias of the Federal University of Alagoas, Rio Largo, AL. The soils were classified as a compacted Yellow Latossol, Grey Argissoil, Fluvic Neosoil, Quartzanic Neossoil and ortic Chromic Luvissoil. Chemical, physical and mineralogical analyses had been made. The determination of the remaining $\mathrm{P}$ was made in the equilibrium solution. The maximum capacity of adsorption was determined through the remaining phosphorus, using PVC rings which were used as diffusion chambers. The doses of phosphorus had been equivalent to $0,10,20$ and $30 \%$ of the maximum capacity of adsorption. The evaluation of the diffusive flow of phosphorus in the soils was carried out through papers of anionic exchange, using filter-papers saturated with the iron oxide. The experiment was constituted of a factorial arrangement $(6 \times 4)$, corresponding to six soils and four doses of phosphorus. The most sandy soils and the largest dose always showed the largest diffusive fluxes of phosphorus.
\end{abstract}

Key words: CMAP, FCP, diffusion

\footnotetext{
1 Parte da Tese de Doutorado do primeiro autor apresentada à UFPB

2 Instituto de Terras de Alagoas. Av. Duque de Caxias, 1.200, Centro, CEP 57025-050, Maceió, AL. Fone: (82) 3221-0499. E-mail: adelmo-bastos@bol.com.br

3 Departamento de Solos e Engenharia/UFAL. CEP 57100-100, Rio Largo, AL. Fone: (82) 3261-2688. E-mail: jpvc@fapeal.br

${ }^{4}$ Departamento de Solos, Manejo e Água/UFPB. CEP 58397-000, Areia, PB. Fone: (83) 3362-2300. E-mail: ivandro@cca.ufpb.br; rwcraposo@cca.ufpb.br

5 UAEF/UFCG, Campus II, CEP 58700-970, Patos, PB. Fone: (83) 3421-3397. E-mail: jacob_souto@yahoo.com.br
} 


\section{INTRODUÇÃO}

A baixa disponibilidade de fósforo é considerada a principal limitação da produção agrícola em condições úmidas, tropicais e subtropicais. A maioria dos ambientes naturais apresenta condições subestimadas relacionadas aos recursos principalmente no que diz respeito ao fósforo (Hinsinger, 2001).

A difusão é o principal mecanismo de transporte do fósforo no solo, sendo influenciada por vários fatores, tais como interações com colóides da fração argila, seu teor, o conteúdo volumétrico de água e a distância a ser percorrida até as raízes. A forte interação com os colóides do solo faz com que ocorra baixo valor de transporte de fósforo, especialmente em solos tropicais muito intemperizados (Costa, 1998).

A disponibilidade de um nutriente para as plantas é afetada por sua movimentação no solo até a superfície radicular; portanto, é a partir do conhecimento dos mecanismos e fatores que afetam o suprimento de nutrientes às raízes, que será possível avaliar, quantitativamente, a absorção de um nutriente para as plantas. Nos solos tropicais a disponibilidade do fósforo aplicado via fertilizante é, geralmente, limitada em razão da grande quantidade de óxidos de ferro e de alumínio.

O fluxo difusivo de fósforo no solo tem sido estimado diretamente pela utilização de resina de troca iônica (Amer et al., 1995) e pelo uso de papel-filtro impregnado com óxidos de ferro e de alumínio (van der Zee et al., 1987). A restrição ao uso da resina granulada se deve à dificuldade de operacionalização, sobretudo pela dificuldade de separação das partículas do solo, o que tem sido contornado com uso da resina trocadora de íons em forma de membrana.

Trabalhos de pesquisa têm demonstrado que o teor de argila é um fator importante para determinação da adsorção de fósforo nos solos (Godinho et al., 1997; Nunes et al., 2004). Esses resultados são concordantes com os obtidos por Rodrigues (1980), que considera o teor de argila como um dos fatores que mais influenciam a capacidade de adsorção deste nutriente (CMAP).

Vários são os trabalhos que têm demonstrado que, além da quantidade de argila, sua constituição mineralógica é de vital importância na adsorção de fósforo pelos solos, justificado pela energia de ligação entre os átomos do elemento e a superfície ativa de cada fração adsorvente (Motta et al., 2002).

É comum se encontrar relação direta entre os teores de matéria orgânica no solo e a capacidade de adsorção do fósforo, visto que os radicais orgânicos recobrem as superfícies dos óxidos de $\mathrm{Fe}$ e $\mathrm{Al}$, formando uma barreira física (Novais \& Smyth,1999).

O movimento lento do fósforo no solo ocorre principalmente em função da sua elevada reatividade e por estar freqüentemente em teor inferior ao adequado para diversas culturas (Hinsinger, 2001), podendo apresentar indisponibilidade à planta.

Neste trabalho se objetivou avaliar o efeito de diferentes doses de fósforo recomendadas pela CMAP, sobre o fluxo difusivo deste elemento em amostras de solo do Estado de Alagoas.

\section{MATERIAL E MÉTODOS}

O Experimento foi desenvolvido no Laboratório de Solos da Universidade Federal de Alagoas - UFAL, no Centro de Ciências Agrárias, em cujo ensaio se utilizou amostras da camada de 0-20 cm de seis solos do Estado de Alagoas.

Os solos foram classificados de acordo com EMBRAPA (1999) como Latossolo Amarelo coeso - LAx, textura francoargilo-arenosa e Argissolo Acinzentado - PAC, textura franco-argilo-arenosa, ambos coletados na região dos tabuleiros de Maceió; Neossolo Flúvico - RU, textura franco-arenosa, coletado no município de Capela; Neossolo Quartzarênico - RQ, textura franco-arenosa; Luvissolo Crômico órtico - TCo, textura franco-argilo-arenosa e Luvissolo Crômico pálico - TCp, textura franco-argilo-arenosa, os três últimos coletados no município de Campo Grande. As amostras foram secadas ao ar, destorroadas, passadas em peneiras de malha de $2 \mathrm{~mm}$ de abertura e homogeneizadas retirando-se, em seguida, subamostras para caracterização química, física e mineralógica, por difração de raios $\mathrm{X}$, montagem em pó, de acordo com o método adaptado de Moore \& Reynolds Jr. (1989) (Tabela 1 e Figura 1). Após as análises, as amostras receberam corretivos

Tabela 1. Atributos químicos e físicos das amostras dos solos (Latossolo Amarelo coeso - LAx; Argissolo Acinzentado - PAC; Neossolo Flúvico - RU; Nessolo Quartzarênico - RQ; Luvissolo Crômico pálico - TCp e Luvissolo Crômico órtico - TCo)

\begin{tabular}{|c|c|c|c|c|c|c|}
\hline \multirow{2}{*}{ Atributos } & \multicolumn{6}{|c|}{ Solos } \\
\hline & LAx & PAC & RU & RQ & TCo & TCp \\
\hline pH em $\mathrm{H}_{2} \mathrm{O}(1: 2,5)^{(1)}$ & 5,60 & 5,80 & 6,00 & 6,00 & 5,60 & 6,10 \\
\hline P-Mehlich $\left(\mathrm{mg} \mathrm{dm}^{-3}\right)^{(1)}$ & 2,00 & 4,00 & 3,00 & 2,00 & 3,00 & 3,00 \\
\hline $\mathrm{Ca}+\mathrm{Mg}\left(\mathrm{cmol}_{\mathrm{c}} \mathrm{dm}^{-3}\right)^{(1)}$ & 3,60 & 2,90 & 2,50 & 6,10 & 5,30 & 11,30 \\
\hline $\mathrm{K}\left(\mathrm{mg} \mathrm{dm}^{-3}\right)^{(1)}$ & 37,00 & 28,00 & 38,00 & 116,00 & 220,00 & 220,00 \\
\hline $\mathrm{Na}\left(\mathrm{mg} \mathrm{dm}^{-3}\right)^{(1)}$ & 4,00 & 8,00 & 10,00 & 35,00 & 18,00 & 37,00 \\
\hline $\begin{array}{l}\text { C. orgânico } \\
\left(\text { dag } \mathrm{kg}^{-1}\right)^{(1)}\end{array}$ & 2,05 & 1,75 & 2,38 & 2,55 & 1,92 & 2,05 \\
\hline P-reman. $\left(\mathrm{mg} \mathrm{L}^{-1}\right)^{(2)}$ & 4,67 & 5,31 & 14,53 & 14,21 & 6,00 & 6,0 \\
\hline CMAP $\left(m g ~ d m^{-3} P\right)^{(3)}$ & $1.541,66$ & $1.520,55$ & $1.355,08$ & $1.358,74$ & $1.500,46$ & $1.489,86$ \\
\hline $\mathrm{Al}\left(\mathrm{cmol}_{\mathrm{c}} \mathrm{dm}^{-3}\right)^{(1)}$ & 0,04 & 0,01 & 0,16 & 0,05 & 0,15 & 0,10 \\
\hline $\mathrm{H}+\mathrm{Al}\left(\mathrm{cmol}_{\mathrm{c}} \mathrm{dm}^{-3}\right)^{(1)}$ & 3,00 & 2,50 & 2,30 & 2,25 & 3,45 & 3,75 \\
\hline $\mathrm{T}\left(\mathrm{cmol}_{\mathrm{c}} \mathrm{dm}^{-3}\right)$ & 6,69 & 5,47 & 4,89 & 8,80 & 9,39 & 15,77 \\
\hline V (\%) & 55,19 & 54,31 & 53,04 & 74,00 & 63,00 & 76,00 \\
\hline M (\%) & 1,07 & 0,33 & 5,80 & 1,00 & 2,00 & 1,00 \\
\hline PST (\%) & 0,00 & 1,00 & 1,00 & 2,00 & 1,00 & 1,00 \\
\hline Areia grossa $\left(\mathrm{g} \mathrm{kg}^{-1}\right)^{(1)}$ & 480,00 & 580,00 & 420,00 & 300,00 & 280,00 & 330,00 \\
\hline Areia fina $\left(\mathrm{g} \mathrm{kg}^{-1}\right)^{(1)}$ & 80,00 & 200,00 & 320,00 & 240,00 & 240,00 & 220,00 \\
\hline Silte $\left(\mathrm{g} \mathrm{kg}^{-1}\right)$ & 150,00 & 20,00 & 150,00 & 350,00 & 180,00 & 260,00 \\
\hline Argila $\left(\mathrm{g} \mathrm{kg}^{-1}\right)$ & 290,00 & 200,00 & 110,00 & 110,00 & 300,00 & 190,00 \\
\hline Silte/Argila & 0,52 & 0,10 & 1,36 & 3,18 & 0,60 & 1,37 \\
\hline Densid. solo $\left(\mathrm{g} \mathrm{cm}^{3}\right)^{(1)}$ & 1,28 & 1,39 & 1,58 & 1,42 & 1,34 & 1,38 \\
\hline $\begin{array}{l}\text { Densid. partícula } \\
\left(\mathrm{g} \mathrm{cm}^{3}\right)^{(1)}\end{array}$ & 2,65 & 2,65 & 2,65 & 2,65 & 2,65 & 2,65 \\
\hline Porosid. Total (\%) & 52,00 & 47,00 & 40,00 & 46,00 & 49,00 & 48,00 \\
\hline $\begin{array}{l}\text { Umidade a }-33 \mathrm{kPa} \\
\text { (\% massa) }\end{array}$ & 16,20 & 9,60 & 10,10 & 10,60 & 17,90 & 13,90 \\
\hline $\begin{array}{l}\text { Umidade a -1500 kPa } \\
\text { (\% massa) }\end{array}$ & 11,90 & 7,00 & 4,10 & 5,10 & 11,40 & 8,60 \\
\hline $\begin{array}{l}\text { Classif. textural } \\
\text { (SBCS)(4) }\end{array}$ & FAA & FAA & FA & FA & FAA & FAA \\
\hline
\end{tabular}

(1) EMBRAPA (1997). (2) Fósforo em equilíbrio após agitação por $1 \mathrm{~h}$, com solução de $\mathrm{CaCl}_{2}$ $0,01 \mathrm{~mol} \mathrm{~L}^{-1}$ com $60 \mathrm{mg} \mathrm{L}^{-1}$ de $\mathrm{P}$ (Alvarez Venegas, 1982; Alvarez Venegas \& Fonseca, 1990). (3) CMAP (Novais \& Kamprath, 1979). (4) FAA - Franco-argilo-arenoa, FA - Franco-arenosa 
Arg 1. Latossolo Amarelo coeso - LAx [ARG-1.RAW]

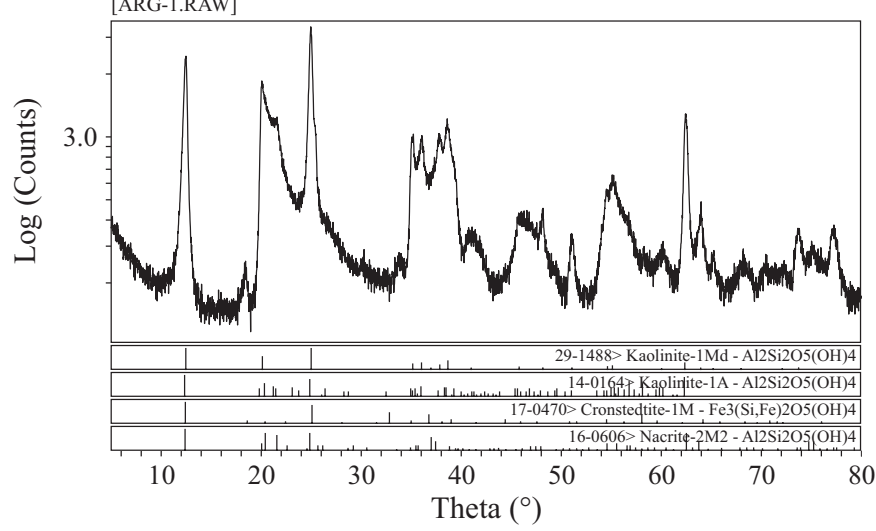

Arg 2. Argissolo Acinzentado - PAC

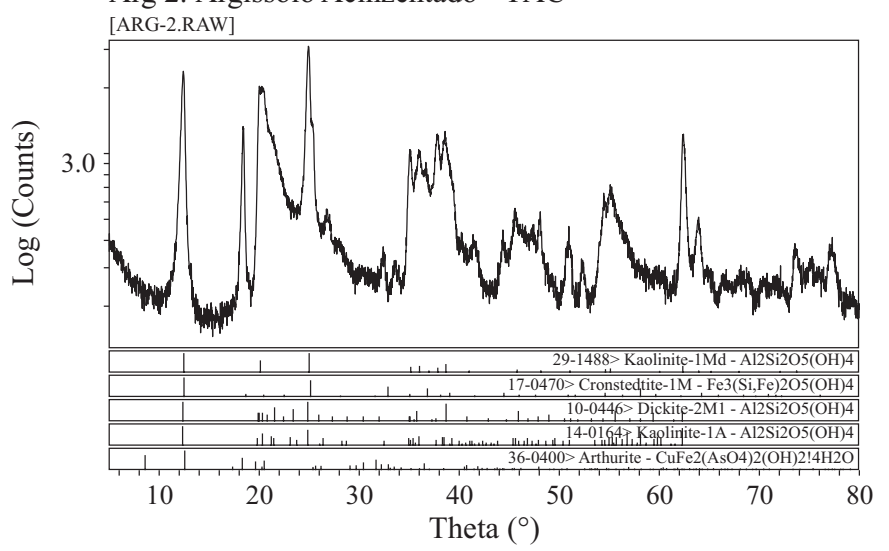

Arg 3. Neossolo Flúvico - RU

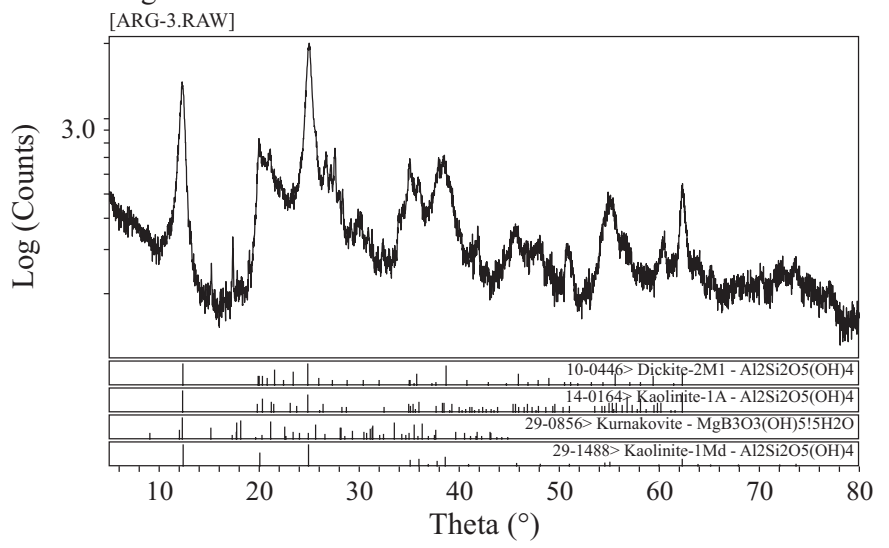

Arg 4. Neossolo Quartzarênico - RQ

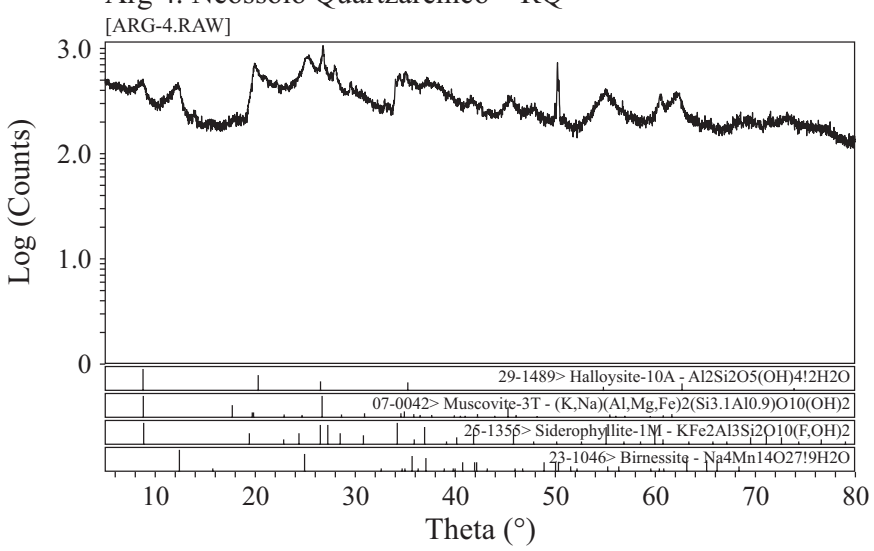

Arg 5. Luvissolo Crômico órtico - TCo

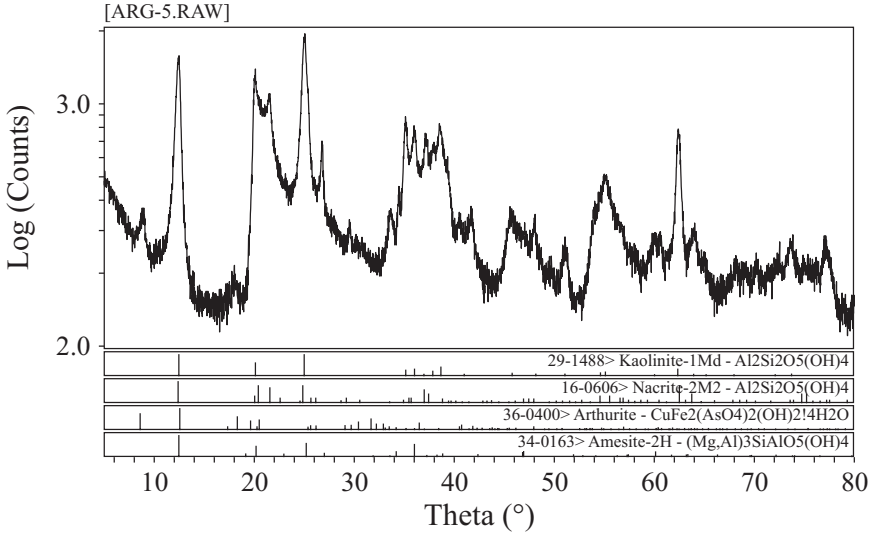

Arg 6. Luvissolo Crômico pálico - TCp

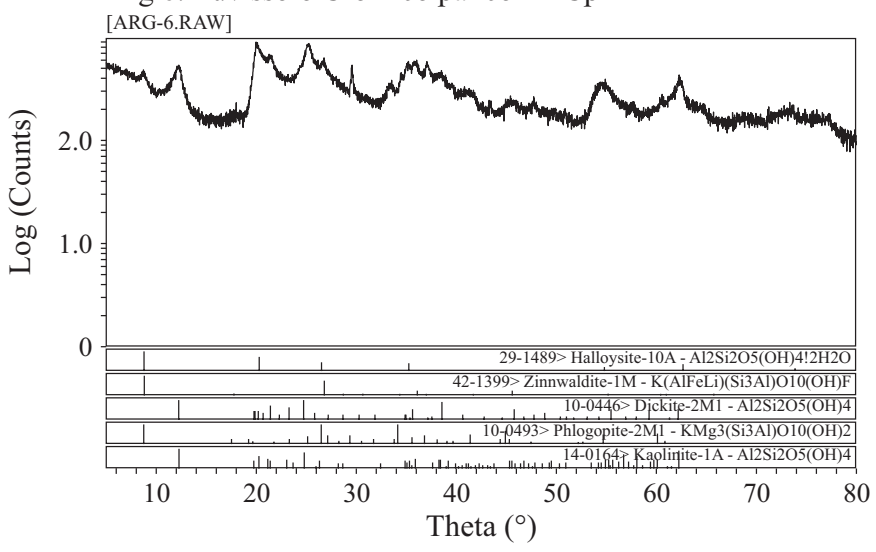

Figura 1. Difratogramas de raios-X da fração argila (Arg) das amostras dos seis solos estudados (montagem em pó)

$\left(\mathrm{CaCO}_{3}\right.$ p.a.) pelo método de saturação por alumínio e foram incubadas em sacos plásticos, durante 30 dias; a umidade foi mantida em torno de $80 \%$ da Capacidade de Campo. O P remanescente foi determinado na solução de equilíbrio após agitação de uma amostra de solo de $5 \mathrm{~cm}^{3}$ com $50 \mathrm{~mL}$ de solução de $\mathrm{CaCl}_{2}$ 0,01 mol L-1 , contendo $60 \mathrm{mg} \mathrm{L}^{-1}$ de P, durante uma hora (Alvarez Venegas, 1982; Alvarez Venegas \& Fonseca, 1990). A capacidade máxima de adsorção do P foi determinada de acordo com Novais \& Kamprath (1979).

Como unidades experimentais utilizaram-se anéis de PVC com $5 \mathrm{~cm}$ de altura e $10 \mathrm{~cm}$ de diâmetro interno,com volume de solo de $300 \mathrm{~cm}^{3}$ que serviram como câmara de difusão.

As doses de fósforo corresponderam a 0, 10, 20 e 30\% da capacidade máxima de adsorção do fósforo (CMAP). O fósforo foi aplicado ao solo via solução, utilizando-se como fonte o fosfato de potássio monobásico $\left(\mathrm{KH}_{2} \mathrm{PO}_{4}\right)$.

Utilizou-se, para avaliação do fluxo difusivo de fósforo (FDP) nos solos, papel de troca aniônica (PA). O PA foi preparado através do papel-filtro FRAMEX $389^{3}$, filtração lenta, de $11 \mathrm{~cm}$ de diâmetro, imerso em solução de $\mathrm{FeCl}_{3} \cdot 6 \mathrm{H}_{2} \mathrm{O}$ $0,4 \mathrm{~mol} \mathrm{~L}^{-1}$ durante $15 \mathrm{~s}$, em que cada folha foi posta sobre uma superfície lisa (vidro) para eliminação do excesso de cloreto de fero, pressionando-se a folha tratada com outra ainda limpa, com o intuito de evitar precipitação desuniforme do hidróxido de ferro; em seguida, transferiu-se a folha tratada para uma solução de $\mathrm{NH}_{4} \mathrm{OH} 2,7 \mathrm{~mol} \mathrm{~L}^{-1}$, também por 15 segundos o que, de imediato, causou mudança da cor do papel, de amarelo para marrom-avermelhado, indicando a 
formação de hidróxido de ferro (Villani, 1995). Ao ser retirado da solução de hidróxido de amônio, o papel foi lavado com água destilada e colocado para secar em varais, preso por pregadores de plástico; depois de seca, a folha tratada foi cortada em tiras de $14 \mathrm{~cm}^{2}$ fixadas lateralmente, com fita adesiva, à superfície de uma lâmina de microscópio, que serviu como suporte para o papel aniônico, PA (Figura 2).

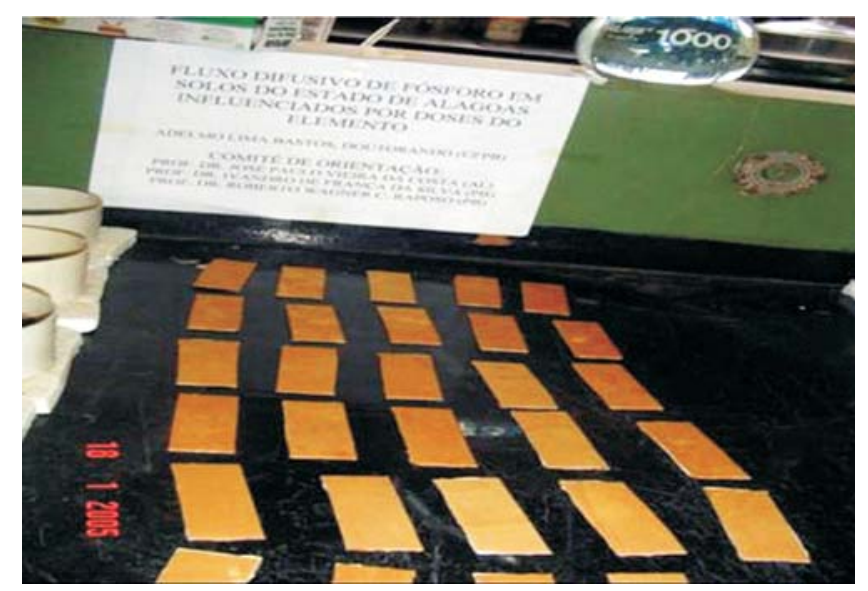

Figura 2. Lâminas de papel de troca aniônica utilizadas no experimento (PA)

De início, cada câmara de difusão recebeu metade do volume do solo das amostras com os tratamentos correspondentes às doses de fósforo. A lâmina de papel de troca aniônica, com área de $10 \mathrm{~cm}^{2}(5 \times 2 \mathrm{~cm})$ e espessura de $0,57 \mathrm{~mm}$, foi disposta horizontalmente e o volume restante do solo foi colocado na câmara.

O trabalho foi conduzido em laboratório, durante 15 dias (Figura 3); após este período, as lâminas foram retiradas e lavadas com jatos de água, para limpeza do solo aderido, enquanto o excesso de água foi retirado com papel filtro.

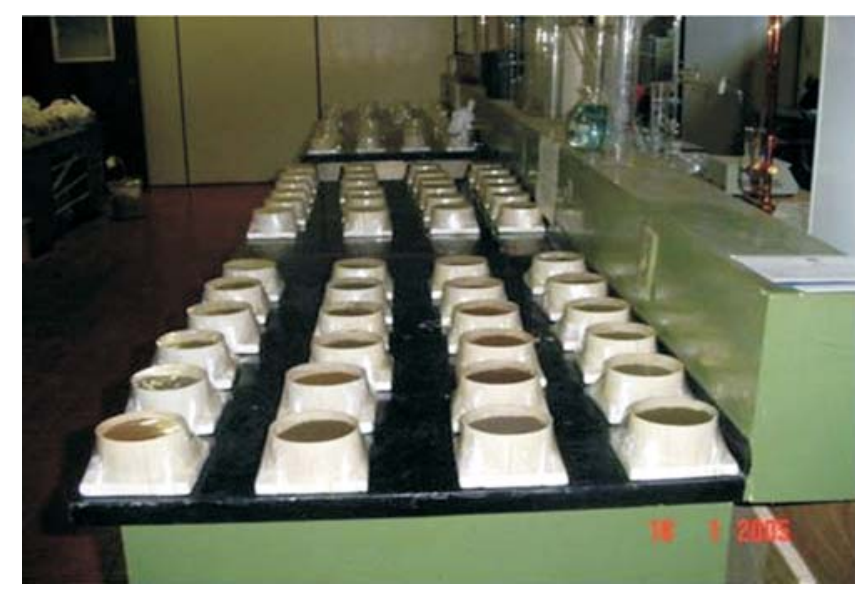

Figura 3. Condução do experimento em laboratório

O fósforo adsorvido pelo Papel Aniônico, PA, foi extraído pela agitação do papel com $50 \mathrm{~mL}$ de uma solução de $\mathrm{NH}_{4} \mathrm{Cl}$ 0,8 mol L-1 $+\mathrm{HCl} 0,2 \mathrm{~mol} \mathrm{~L}^{-1}$ durante uma hora, em agitador horizontal a 270 rotações por minuto, utilizandose metodologia descrita por van Raij et al. (1987). A con- centração de fósforo foi determinada no colorímetro, de acordo com Braga \& Defelipo (1974). A estimativa da difusão (fluxo difusivo) foi realizada pela quantificação do fósforo adsorvido ao PA, que corresponde ao fósforo que atingiu a resina no período de 15 dias.

$\mathrm{O}$ ensaio consistiu em um arranjo fatorial (6 x 4) correspondendo, respectivamente, a seis solos, quatro doses de fósforo recomendadas pela capacidade máxima de adsorção do fósforo (0, 10, 20 e 30\% da CMAP), com quatro repetições, perfazendo o total de 24 tratamentos, com 96 parcelas, em blocos casualizados; além das análises de variância para os solos, as doses e interação doses x solos, realizou-se também o teste de média (Tukey) para as variáveis fluxo difusivo do $\mathrm{P}$ e pH, além de feitas também as análises de regressão; quando se encontrou efeito significativo pelo teste $\mathrm{F}$ para determinada causa de variação, efetuou-se o desdobramento das regressões, utilizando-se o teste $\mathrm{F}$ e o coeficiente de determinação para então se escolher a equação de regressão que melhor se ajustasse aos resultados, através do programa estatístico SAEG 5.0.

\section{RESULTADOS E DISCUSSÃO}

Observou-se que, em cada solo, o FDP apresentou diferença significativa nas doses equivalentes a 0, 10, 20 e 30\% da CMAP, sendo que a dose equivalente a $30 \%$ da CMAP indicou os maiores resultados entre os seis solos estudados; constatou-se, em todos os solos, sempre que se aumentava a dose de P, que FDP era maior; esses resultados concordam com Horst et al. (2001), quando afirmam que, quanto mais fósforo disponível no solo maior será o gradiente de concentração deste elemento, razão pela qual ocorreu o aumento do FDP; este fato também pode ser discutido em relação ao entendimento de Godinho et al. (1997) e Costa (1998), de que ao aumento da dose de fósforo haverá sempre um aumento do coeficiente de difusão do elemento devido à saturação progressiva da superfície da adsorção, o que resultará no aumento da concentração do elemento.

Uma comparação que demonstra o contraste entre os solos (Tabela 2) é aquela entre os tratamentos com 0 e a dose $10 \%$ da CMAP; enquanto para o LAx e PAC houve um aumento real de 1,6 e 2,15 vezes respectivamente e o aumento

Tabela 2. Fluxo difusivo do $\mathrm{P}$ em função de doses de $\mathrm{P}$ recomendadas pela CMAP, em solos distintos

\begin{tabular}{ccccc}
\hline \multirow{2}{*}{ Solos } & \multicolumn{4}{c}{ Doses de fósforo recomendadas em função da CMAP (\%) } \\
\cline { 2 - 5 } & $\mathbf{0}$ & $\mathbf{1 0}$ & $\mathbf{2 0}$ & $\mathbf{3 0}$ \\
LDF $\left(\mathrm{mg} \mathrm{dm}^{-3}\right)$ & $15 \mathrm{dias}$ \\
LAx & $0,049 \mathrm{Db}$ & $0,128 \mathrm{Ce}$ & $0,180 \mathrm{Bf}$ & $0,218 \mathrm{Af}$ \\
PAC & $0,048 \mathrm{Db}$ & $0,151 \mathrm{Cd}$ & $0,189 \mathrm{Be}$ & $0,262 \mathrm{Ae}$ \\
RU & $0,051 \mathrm{Db}$ & $0,233 \mathrm{Ca}$ & $0,386 \mathrm{Bb}$ & $0,452 \mathrm{Ab}$ \\
RQ & $0,032 \mathrm{Dc}$ & $0,218 \mathrm{Cb}$ & $0,419 \mathrm{Ba}$ & $0,529 \mathrm{Aa}$ \\
TCo & $0,061 \mathrm{Da}$ & $0,233 \mathrm{Ca}$ & $0,363 \mathrm{Bc}$ & $0,393 \mathrm{Ac}$ \\
TCp & $0,050 \mathrm{Db}$ & $0,190 \mathrm{Cc}$ & $0,259 \mathrm{Bd}$ & $0,346 \mathrm{Ad}$ \\
\hline
\end{tabular}

Médias seguidas de mesma letra minúscula na coluna e maiúscula na linha, não diferem estatisticamente a $5 \%$ de probabilidade pelo teste de Tukey. Latossolo Amarelo coeso - Lax; Argissolo Acinzentado - PAC; Neossolo Flúvico - RU; Nessolo Quartzarênico - RQ; Luvissolo Crômico pálico- TCp e Luvissolo Crômico órtico- TCo 
real no RU e RQ corresponde a 3,57 e 5,81 vezes, cuja comparação demonstra a influência da argila na adsorção do fósforo (Nunes et al., 2004).

A análise dos difratogramas de raios- $X$ da fração argila (Figura 1) evidenciou a presença da caulinita como mineral predominante, exceção apenas do RQ, que apresentou a haloisita, que é um mineral pertencente ao grupo da caulinita, assim como a nacrita (LAx e TCo) e dicrita (PAC e RU); desta forma e em razão da maior eletronegatividade, os valores de $\mathrm{P}$ remanescente foram mais elevados e os da CMAP foram mais baixos do que normalmente encontrados em solos mais intemperizados (LAx) (Fonseca, 1987). Bognola (1995) encontrou valores de CMAP entre 1.620 e $2.740 \mathrm{mg} \mathrm{dm}^{-3} \mathrm{P}$, em Latossolos derivados de rochas basálticas. Esses valores indicam a importância da mineralogia no processo de adsorção de fosfatos no solo (Carrasco et al., 1992). A participação da caulinita no processo de adsorção de P é secundária, em comparação com os componentes óxidos. Ker (1995) notou que o aumento do caráter caulinítico em diversos Latossolos do Brasil provocava redução da capacidade de adsorção de fósforo.

O problema da difusão de $\mathrm{P}$ nos solos com maior adsorção fica mais evidente quando se tem, com a adição de $20 \%$ da CMAP no LAx e PAC, menor difusão que o RU e RQ com dose de $10 \%$ da CMAP, ou seja, mesmo aumentando uma vez a dose, o FDP foi menor. Esses resultados estão de acordo com os de Villani (1995), ao avaliar o FDP em solos do Estado de Minas Gerais.

Comparando-se os seis solos, verifica-se que o maior FDP ocorreu no solo RQ, associado à maior dose, 30\% da CMAP e que os valores do FDP foram muito baixos quando o P estava na dose $0 \%$ da CMAP. Acréscimos muito maiores foram verificados entre as doses 0 e $10 \%$ da CMAP que nas doses 20 e $30 \%$ da CMAP, em todos os solos. Na dose 30\% da CMAP, o FDP no RQ correspondeu a um aumento real de 1,43 vez o valor observado no LAx; para o RU, o FDP real foi 0,73 vez maior que o PAC, o que reflete a diferença no fator capacidade de $\mathrm{P}$ desses solos, motivada pela textura dos mesmos. Pode-se observar, ainda quando se duplica a dose de P de 10 para 20\% da CMAP, no RU e RQ, que a difusão aumenta mais do que quando se dobra a dose nos LAx, PAC, TCo e TCp, indicando maior efetividade do aumento da dose de fósforo no FDP no solo mais arenoso. Costa (1998) e Villani et al. (1993), encontraram comportamentos semelhantes trabalhando com solos de diferentes texturas e doses de fósforo. A CMAP vem sendo estudada ao longo dos anos e foi inicialmente utilizado, como critério para estimar a quantidade desse nutriente a ser adicionada ao solo com vistas a promover um crescimento adequado das plantas (Braga \& Defelipo, 1974; Vasconcellos et al., 1975); este critério, entretanto, nem sempre tem apresentado boa capacidade preditiva (Novais \& Kamprath, 1979).

Os aumentos mais acentuados do FDP nos solos mais arenosos, quando se aumentam as doses de P, em comparação com os menores acréscimos nos solos mais argilosos, até mesmo quando recebem doses mais elevadas, mostram que pequenas alterações no fator intensidade são conseguidas com altas doses de P nos solos argilosos. Em virtude do fator capacidade desses solos ser elevado, só se obtêm pequenas alterações no P na solução do solo com a aplicação de doses muito elevadas, que já não são mais econômicas (Novais \& Smyth, 1999).

De maneira geral, os solos mais arenosos apresentaram um FDF maior, uma vez que a resistência dos solos arenosos a mudanças no fator intensidade de P é menor que nos solos argilosos; este fato pode estar ligado, também, à maior energia de adsorção dos solos argilosos. Para Holford (1980) solos com maior energia de adsorção convertem facilmente fósforo lábil em não lábil diminuindo, desta forma, sua disponibilidade. No cultivo do milho é comum a obtenção de maior produtividade em solos de cerrado com textura média e arenosa que em solos argilosos, fato este de relevância, uma vez que a maioria das áreas de produção da cultura é de textura média; tal verificação é entendida pela limitada difusão de P nos solos argilosos com maior relação de adsorção comparativamente àquela verificada nos solos de textura mais arenosa (Tabela 2). Observa-se que nos solos mais argilosos, LAx e PAC, mesmo com doses de fósforo maior que as testadas no RU e RQ (solos mais arenosos), a difusão foi menor, indicando ser mais efetivo aumentar a dose de $\mathrm{P}$ no solo mais arenoso que no argiloso.

Normalmente, quando se aplica uma fonte solúvel de $\mathrm{P}$ em um solo, mais de $90 \%$ do aplicado são adsorvidos na primeira hora de contato com o solo (Gonçalves et al., 1985); esta adsorção de $\mathrm{P}$ pelo solo apresenta um componente adicional à simples formação de P-lábil (Q), que é a formação de P-não lábil; este é a quantidade de fósforo adsorvida que não se encontra em equilíbrio com o P-solução.

Para os estudos e pesquisas de adsorção e de difusão do fósforo nos solos, é importante conhecer os teores de argila e a identificação do mineral, cristalinidade e tamanho médio do cristal. A determinação do tamanho ou grau de cristalinidade dos minerais na fração argila é muito importante, pois fenômenos como adsorção de fosfatos, por exemplo, dependem desses aspectos (Ker, 1995; Kampf \& Curi, 2003;). Observou-se, através dos dados obtidos, que o FDP foi influenciado principalmente pelo teor de argila, o que concorda com os obtidos por Rodrigues (1980), ao considerar o teor de argila um dos fatores que mais influenciam a capacidade de adsorção do P.

Os maiores valores do FDP no PA encontrados no RU e RQ podem ser justificados em função do seu menor teor de argila, concordando com Almeida et al. (2003), ao estudarem a adsorção de fosfatos em latossolos..

A Tabela 3 apresenta as equações de regressão do FDP em função das doses de P recomendadas pela CMAP aplicados nos solos. Verificou-se que os dados do fluxo difusivo do $\mathrm{P}$ se ajustaram a uma equação de regressão quadrática, com

Tabela 3. Equações de regressão relacionando o fluxo difusivo de fósforo (mg dm ${ }^{-3}$ por 15 dias) com as doses de fósforo dentro dos solos utilizados

\begin{tabular}{|c|c|c|}
\hline Solo & Equações de regressão & $\mathbf{R}^{2}$ \\
\hline LAx & $y=0,0497+0,0087 x^{\star *}-0,0001 x^{2 \star *}$ & 0,99 \\
\hline PAC & $y=0,053+0,009 x^{\star \star}-0,00008 x^{2 \star \star}$ & 0,98 \\
\hline $\mathrm{RU}$ & $y=0,0481+0,0223 x^{\star *}-0,0003 x^{2 \star *}$ & 0,99 \\
\hline $\mathrm{RQ}$ & $y=0,0267+0,0226 x^{\star *}-0,0002 x^{2 \star *}$ & 0,99 \\
\hline $\mathrm{TCo}$ & $y=0,0581+0,0219 x^{\star *}-0,0004 x^{2 \star *}$ & 0,99 \\
\hline TCp & $y=0,0545+0,0135 x^{\star *}-0,0001 x^{2 \star *}$ & 0,99 \\
\hline
\end{tabular}

Latossolo Amarelo Coeso - Lax; Argissolo Acinzentado - PAC; Neossolo Flúvico - RU; Nessolo Quartzarênico - RQ; Luvissolo Crômico pálico - TCp e Luvissolo Crômico órtico - TCo 
boa capacidade preditiva, cujos coeficientes de determinação explicam o efeito das doses de P recomendadas pela CMAP sobre a variável analisada. As doses de máxima eficiência técnica equivalem a 43,5, 56,25, 37,16, 56,5, 27,37 e 67,5\% da CMAP para um fluxo difusivo máximo de 0,24, 0,31, 0,46, 0,66, 0,66 e 0,51 $\mathrm{mg} \mathrm{dm}^{-3}$ por 15 dias, respectivamente, para o LAx, PAC, RU, RQ, TCo, e TCp.

A utilização de papéis de filtro impregnados com óxido de ferro para extração de $\mathrm{P}$ do solo e, conseqüentemente, a determinação do fluxo difusivo, é limitada por diversos fatores, podendo-se destacar a dificuldade da preparação uniforme dos papéis aniônicos, o manuseio da extração e a possibilidade de contaminação dos extratos, tendo em vista as pequenas quantidades extraídas (Miola et al., 1999).

\section{CONCLUSÕES}

1. Os solos mais arenosos (Neossolo Flúvico, RU e Neossolo Quartzarênico, RQ) apresentaram maior fluxo difusivo que os argilosos.

2. O maior fator capacidade de P dos Latossolo Amarelo coeso, LAx, Neossolo Quartzarênico, RQ, Luvissolo Crômico pálico, TCp e Luvissolo Crômico órtico, TCo influenciou para que o fluxo difusivo do $\mathrm{P}$ tenha sido menor nesses solos.

3. A dose de $30 \%$ da CMAP apresentou maior fluxo difusivo do $\mathrm{P}$ em todos os solos, relacionados às demais.

\section{AGRADECIMENTOS}

Os autores agradecem à Fundação de Amparo à Pesquisa do Estado de Alagoas/FAPEAL pelo apoio financeiro, a UFAL e a UFPB, pelo apoio concedido a esta pesquisa.

\section{LITERATURA CITADA}

Alvarez Venegas, V. H. Efecto de los factores cantidad, intensidad y capacidad amortiguadora de fosfatos en la evaluación del fósforo disponible de suelos derivados de cenizas volcánicas de la Meseta Tarasca. Capingo: Colégio de Pos-Graduados, Edo. Michoacán, 1982. 300p. Tese Doutorado

Alvarez Venegas, V. H.; Fonseca, D. M. Definição de doses de fósforo para a determinação da capacidade máxima de adsorção de fosfatos para ensaios em casa de vegetação. Revista Brasileira de Ciência do Solo, v.14, p.49-55, 1990.

Almeida, J. A.; Torrent, J.; Barrón, V. Cor de solo, formas de fósforo e adsorção de fosfatos em Latossolos desenvolvidos de Basalto do extremo sul do Brasil. Revista Brasileira de Ciência do Solo, v.27, n.6, p.985-1002, 2003.

Amer, F.; Boundin, D. R.; Black, C. A.; Duke, F. R. Characterizations ol soil phosphorus by anion exchange resin adsorption ond P-equilibrations. Plant and Soil, v.6, n.4, p.391-408, 1995.

Bognola, I. A. Caracterização química, física e mineralógica de solos intermediários entre Latossolos Brunos e Latossolos Roxos. Viçosa: UFV, 1995. 205p. Dissertação Mestrado
Braga, J. M.; Defelipo, B. V. Determinação espectrofométrica do fósforo em extratores de solos e plantas. Revista Ceres, v.21, n.113, p.73-85, 1974.

Carrasco, R. M. A.; Opazo, A. J.; Peralta, I. V.;Vera, Q. L. Retencion de fósforo em suelos de zonas semiáridas. Agricultura Técnica, v.52, n.8, p.411-415, 1992.

Costa, J. P. V. da Fluxo difusivo de fósforo e de potássio em latossolos.Viçosa: UFV, 1998. 67p. Tese Doutorado

EMBRAPA - Empresa Brasileira de Pesquisa Agropecuária Manual de métodos de análise de solo. 2.ed. Rio de Janeiro: Embrapa CNPS, 1997. 212p.

EMBRAPA - Empresa Brasileira de Pesquisa Agropecuária - Sistema Brasileiro de classificação de solos. Rio de Janeiro: Embrapa CNPS, 1999, 412p.

Fonseca, D. M. Níveis críticos de fósforo em amostras de solos para o estabelecimento de Andropogon gayanus, Brachiaria decumbens e Hyparhenia rufa. Viçosa: UFV, 1987. 146p. Dissertação Mestrado

Godinho, V. de P. C.; Sampaio, R. A.; Alvarez Venegas, V. H.; Ruiz, H. A. Adsorção de fosfatos em três solos da região SemiÁrida do Rio Grande do Norte. Pesquisa Agropecuária Brasileira, v.32, n.8, p.19-823, 1997.

Gonçalves, J. L. M.; Firme, D. J.; Novais, R. F.; Ribeiro, A. C. Cinética de adsorção de fósforo em solos de cerrado. Revista Brasileira de Ciência do Solo, v.9, n.2, p.107-111, 1985.

Hinsinger, P. Biologyavailability of soil inorganic P in the rhizosphere as affected by root-induced chemical changes: A review. Plant and Soil, v.237, n.2, p.173-195, 2001.

Holford, I. C. D. Effects of phosphate buffer capacity oncritical levls and relationship between soil test labile phosphate in wheat growing soil. Soil Science Society of America Journal, v.18, n.4, p.404-414, 1980.

Horst, W. J.; Kamh, M; Jibrin, J. M.; Chude, V. O. Agronomic measurements for increasing $P$ availability to crops. Plant and Soil, v.237, n.2, p.211-223, 2001.

Kampf, N.; Curi, N. Argilominerais em solos brasileiros. In: Curi, N.; Marques, J. J. G. S. M.; Guilerme, L. R. G.; Lima, J. M.; Lopes, A. S.; Alvarez Venegas, V. H (eds.) Tópicos em Ciência do Solo. V.III. Viçosa: Sociedade Brasileira de Ciência do Solo, 2003. p.1-54.

Ker, J. C. Mineralogia, sorção e dessorção de fosfato, magnetização e elementos traços de Latossolos do Brasil. Viçosa: UFV, 1995. 181p. Tese Doutorado

Miola, G. R.; Tedesco, M. J.; Bissani, C. A.; Gianello, C.; Camargo, F. A. de O. Avaliação da disponibilidade de fósforo no solo para a cultura do milho. Pesquisa Agropecuária Brasileira, v.34, n.5, p.813-819, 1999.

Moore, D. M.; Reynolds, Jr. R. C. X-ray diffraction and the identification and anlalysis of clay minerals. New York: Oxford University Press, 1089. 332p.

Motta, P. E. F.; Curi, N.; Siqueira, J. O.; van Raij, B.; Furtii Neto, A. E.; Lima, J. M. Adsorção e formas de fósforo em Latossolos: Influência da mineralogia e histórico de uso. Revista Brasileira de Ciência do Solo, v.26, n.2, p.349-359, 2002.

Novais, R. F.; Kamprath, E. J. Parâmetros das isotermas de adsorção do fósforo como critério de recomendação de adubação fosfatada. Revista Brasileira de Ciência do Solo, v.3, n.1, p.37-41, 1979.

R. Bras. Eng. Agríc. Ambiental, v.12, n.2, p.136-142, 2008. 
Novais, R. F.; Smyth, T. J. Fósforo em solo e planta em condições tropicais. Viçosa: UFV, 1999. 399p.

Nunes, F. N.; Novais, R. F.; Silva, I. R.; Gebrim, F. O.; São José, J. F. B. Fluxo difusivo de ferro em solos sob influência de doses de fósforo e de níveis de acidez e umidade. Revista Brasileira de Ciência do Solo, v. 28, n. 3, p.423-429, 2004.

Rodrigues, M. R. Fatores que afetam a fixação de fosfatos nos solos do Estado de São Paulo. Piracicaba: ESALQ/USP, 1980, 88p. Dissertação Mestrado

van der Zee, S. E. A. T. M.; Fokkink, L. G. J.; van Riemsdijk, W. H. A. New technique for assessment of reversibly adsorbed phosphate. Soil Science Society of America Journal, v.51, n.3, p.599-604, 1987. van Raij, B.; Quaggio, J. A.; Cantarella, H.; Ferreira, M. E.; Lopes, A. S.; Bataglia, O. C. Análise química do solo para fins de fertilidade. Campinas: Fundação Cargil, 1987. 170p.

Vasconcellos, C. A.; Braga, J. M. Novais, R. F.; Pinto, O. C. B. Fósforo em dois Latossolos do Estado de Mato Grosso. III. Relações entre planta solo e fósforo. Revista Ceres, v.22, n.5, p.22-49, 1975.

Villani, E. M. A.; Novais, R. F. Barros, N. F.; Fontes, L. E. F.; Neves, J. C. L. Difusão de fósforo em solos com diferentes texturas e níveis de umidade. Revista Brasileira de Ciência do Solo, v.178, n.3, p.343-347, 1993.

Villani, E. M. A. Fluxo difusivo do fósforo influenciado por fontes e por tempo de contato do fósforo com o solo. Viçosa: UFV, 1995. 57p. Dissertação Mestrado 